\title{
Soft Computing Based Cavity Temperature Control of Plastic Injection Molding system
}

\author{
S. J. Suji Prasad ${ }^{1}$, R. Manjula Devi ${ }^{2}$, R. Meenakumari ${ }^{3}$ \\ ${ }^{1}$ Assistant Professor (SRG), Department of EIE, Kongu Engineering College, Erode \\ sjsujiprasad@gmail.com \\ ${ }^{2}$ Assistant Professor (SRG), Department of CSE, Kongu Engineering College, Erode \\ rmanjuladevi.gem@gmail.com \\ ${ }^{3}$ Professor, Department of EEE, Kongu Engineering College, Erode \\ oremkay@gmail.com
}

\begin{abstract}
The plastic parts having complex three dimensional structures are produced by Plastic injection molding system. The quality of the product is determined by controlling the temperature of the mold cavity. The mold cavity temperature control with the conventional ON/OFF, PI, and PID controllers have several disadvantages. This paper proposes the method to reduce settling time and undershoot in cavity temperature control with selected evolutionary algorithms. The controller parameters are optimized with Genetic Algorithm (GA) and Particle Swarm Optimization (PSO) Algorithm for PID and I-PD controllers by considering Mean Square Error (MSE) as fitness function. Compared to conventional methods the parameter optimization using soft computing methods such as GA and PSO improves the performance indices of PID and I-PD controllers.
\end{abstract}

\section{Indexing terms/Keywords}

I-PD Controller, Mean Square Error (MSE), melt temperature, optimization, settling time, undershoot

\section{INTRODUCTION}

In the modern era, many engineering applications use polymeric materials due to its advantages and properties viz. hardness, tensile strength. The Plastic Injection Molding (PIM) system produces plastic products with desired shape and size. The quality of the final product of the PIM system created interest in researchers to focus on cavity temperature control. The melt temperature plays a vital role and the change in melt temperature during molding should be as small as possible. Since, the load changes will lead to deformation of size, color, shape, dimensions, and quality of the product [12], the melt temperature has to be controlled by proper design of controllers.

The conventional ON/OFF control has its own disadvantage like weak control and chattering. The chattering leads to the undesired shape of the product and the heaters will wear out. The control of mold cavity temperature with Proportional Integral (PI) controller results in an efficient cooling for the Injection molding system [2-3]. PI and PID controllers are predominantly used in all Industrial control applications [4]. But the PID controller has the drawback of proportional kick, which results spike in the controller output. The kick can be avoided by introducing I-PD controller, a variant of PID controller [5-6].

The optimized controller parameters play a major role in improving the performance of the controller. The optimized PID controllers are obtained with Fuzzy logic technique, which improves the performance of the conventional PID controller [78]. Evolutionary optimization techniques like GA (Genetic Algorithm), PSO (Particle Swarm Optimization), BF (Bacterial Foraging), and ACO (Ant Colony Optimization) will result in the optimization of the controller parameters. [9-10]. In this paper, the GA optimized I-PD controller for a PIM system is simulated with mean square error as fitness function and compared with fuzzy PID and convention Ziegler-Nichols PID. The performance of I-PD controller is improved by optimizing I-PD controller parameters with PSO.

The remaining section of the paper is organized as follows: The process of cavity temperature control in PIM and I-PD controller structure is described in Section 2. Ziegler-Nichols (ZN) Tuning of controller parameters and the fuzzy tuned PID and I-PD is described in Section 3. With settling time as optimizing criteria GA based PID and I-PD is proposed for mold cavity temperature control system in Section 4. In section 5, details of PSO algorithm and optimization of controller parameters are detailed. The comparison of simulation results using various methods for controlling the temperature of mold cavity of PIM are presented in Section 6. The findings of the paper are concluded in Section 7.

\section{CAVITY TEMPERATURE CONTROL AND I-PD CONTROLLER}

\subsection{Cavity Temperature Control System}

In PIM, there are four phases of actions viz., filling, packing-holding, cooling, and plastication. Mold cavity temperature is coming under the cooling stage in which the melt, which is injected into the mold cavity, is allowed to cool for the solidification. In this process, the variable to be controlled is the part temperature which is normally achieved by controlling the average temperature of the mold cavity [1]. Variables which directly affect the mold cavity temperature are the flow rate and temperature of the coolant. The flow rate of the coolant can be changed easily compared to the coolant temperature. So the coolant flow rate is taken as the manipulated variable.

The coolant flow rate is changed by changing the pumping speed of the DC motor. The relationship between different flow 
rates indicated by the set of DC motor inputs and the cavity temperature can be achieved by obtaining several open loop test data and then subjected to system identification [2]. The parametric model for system identification is Auto-Regressive Exogenous (ARX) that uses a least squares formulation to relate system inputs and outputs. The obtained $A R X$ model of the plant is converted into a continuous form for further analysis and the process model [2] obtained is given in Equation (1).

$$
G_{p}(s)=\frac{-0.01742 s^{2}-0.003464 s+0.0005151}{s^{2}+0.4216 s^{2}+0.05852 s+0.0002201}
$$

\subsection{I-PD Controller}

The control action of the conventional PID controllers leads to overshoot / undershoot and increased settling time. The I-PD controller shown in Fig. 1.

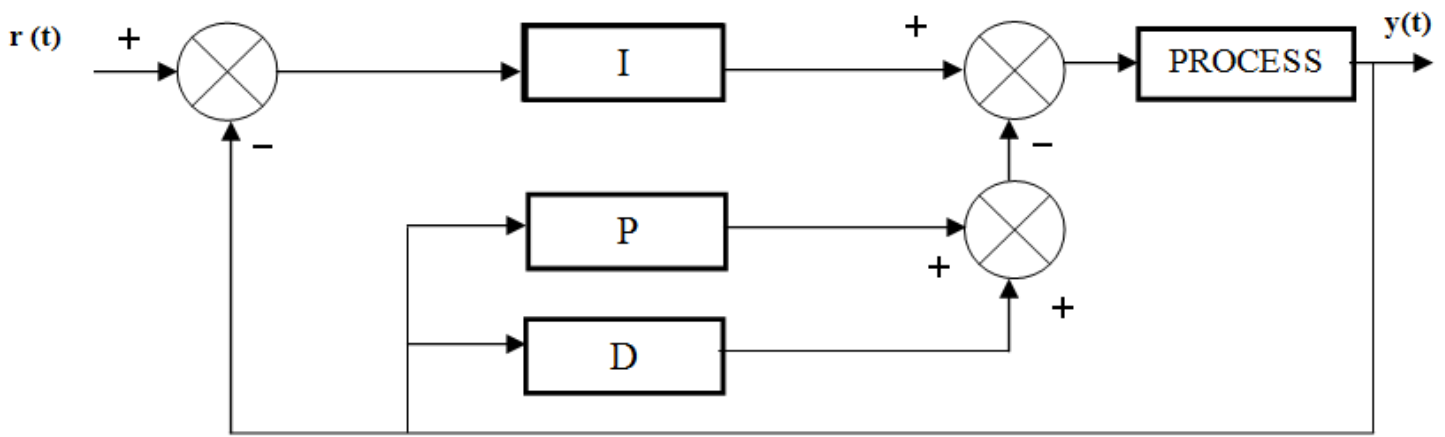

Fig. 1: I-PD controller

From the above figure it is observed that in the modified form of PID controller, the control action $\mathrm{m}(\mathrm{t})$ is based on integral of error $\mathrm{e}(\mathrm{t})$ and proportional and derivative of measured variable $\mathrm{y}(\mathrm{t})$. The controller output of I-PD controller is given by (2).

$$
m(t)=K_{p}\left[e(t)+\frac{1}{T_{i}} \int e(t) d t\left(y(t)+T_{d} \frac{d y(t)}{d t}\right)\right]
$$

\section{ZN AND FUZZY TUNED CONTROLLERS}

In conventional PID controller, the controller gain determines the desired output, and its tuning is a challenge to the researchers.

\subsection{ZN Tuning}

$\mathrm{ZN}$ tuning, is a closed loop tuning method based on quarter decay ratio performance criteria. The controller parameters are obtained with crossover frequency $w$ and amplitude ratio $A[11]$.

$$
\begin{aligned}
& \text { Ultimate } \mathrm{Gain}_{\mathrm{u}}=\frac{1}{\mathrm{~A}} \\
& \text { Period of sustained oscillations } \mathrm{P}_{\mathrm{u}}=\frac{2 \pi}{W}
\end{aligned}
$$

The PID controller parameters are calculated based on the following equations.

$$
\begin{aligned}
& \text { Proportional Gain } K_{p}=0.6 K_{u} \\
& \text { Integral Time } T_{i}=0.5 P_{u} \\
& \text { Derivative Time } T_{d}=0.125 P_{u}
\end{aligned}
$$

\subsection{Fuzzy Tuned Controller}


The PID controller parameters, $\mathrm{Kp}, \mathrm{Ki}$, and $\mathrm{Kd}$ are tuned based on the forty nine set of rules. Error and rate of change of error are the inputs to the fuzzy inference system and $\mathrm{Kp}, \mathrm{Ki}$, and $\mathrm{Kd}$ are outputs. The rules are written in rule editor of fuzzy inference system as shown in Fig. 2.

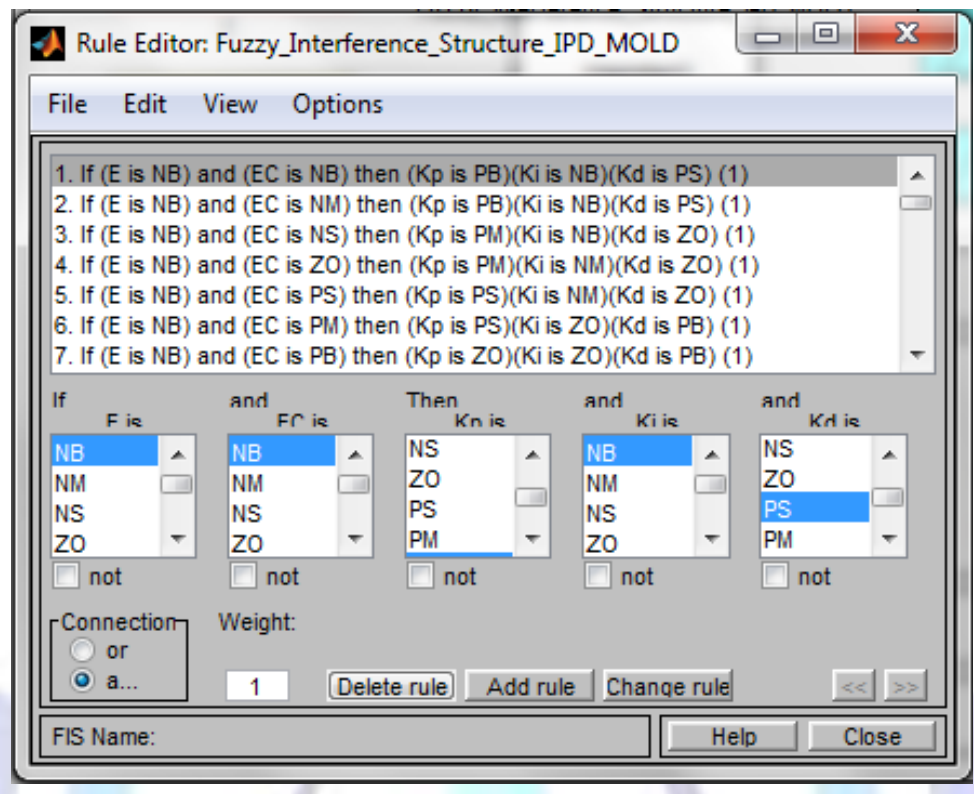

Fig. 2: Rule Editor of Fuzzy Inference System

The ranges of controller parameters are selected based on the gain values obtained during ZN tuning method. The range of $\mathrm{Kp}, \mathrm{Ki}$, and $\mathrm{Kd}$ are selected as 0 to 8,0 to 0.12 and 0 to 0.1 for Fuzzy PID controller and 0 to $2.8,0$ to 0.035 and 0 to 0.1 for Fuzzy I-PD controller respectively.

\section{SOFT COMPUTING BASED PID AND I-PD CONTROLLER}

\subsection{GA based PID and I-PD Controller}

The stochastic global search method Genetic algorithm (GA) mimics the process of natural evolution. In a given search space GA, the probabilistic optimization algorithm starts without the knowledge of correct solutions and gives a good solution. The best solution can be arrived with reproduction, crossover, and mutation as evolution operators [14-16].

The controller tuning performed using genetic algorithm results in the optimum gain values [10]. Objective functions play a major role in Genetic Algorithm in order to tune PID controller parameters. Performance indices such as settling time, overshoot, integral square error, integral absolute error, and mean square error are the criteria mostly used for controller tuning. In this work minimization of Mean Square Error (MSE) is selected as the objective function. The flowchart of the GA optimization algorithm is shown in Fig. 3. 


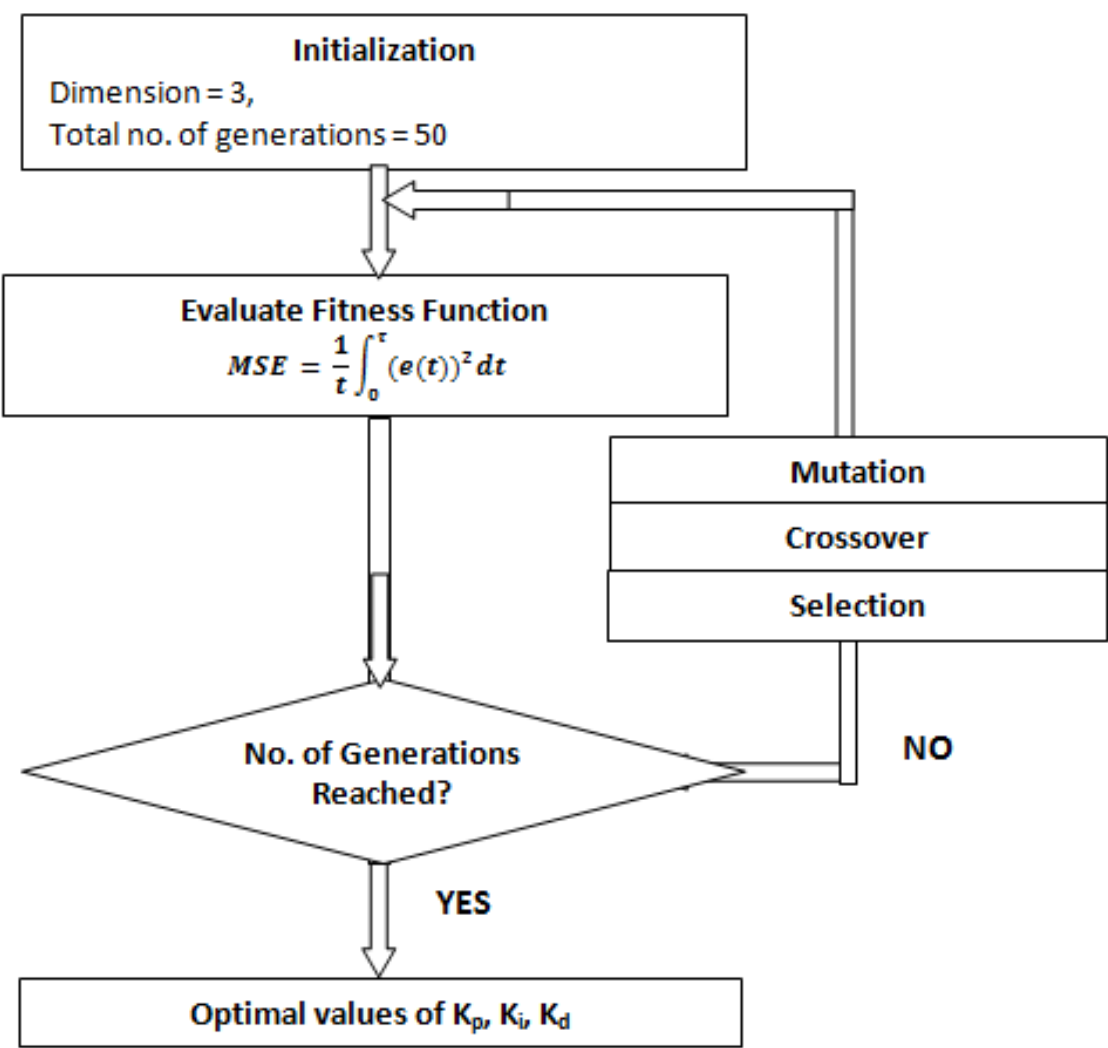

Fig. 3:. Flowchart of GA optimization algorithm

The GA tuned PID and I-PD controller parameter gain values are given in the Table 1.

Table 1: GA Tuned Controller Parameters

\begin{tabular}{|l|c|c|c|}
\hline \multirow{2}{*}{} & \multicolumn{3}{|c|}{ Controller Parameters } \\
\cline { 2 - 4 } & $\mathrm{K}_{\mathrm{p}}$ & $\mathrm{K}_{\mathrm{i}}$ & $\mathrm{K}_{\mathrm{d}}$ \\
\hline GA PID & 7.7613 & 0.2163 & 23.0360 \\
\hline GA I-PD & 8.5292 & 0.3160 & 25.9892 \\
\hline
\end{tabular}

\subsection{PSO based PID and I-PD Controller}

The particle swarm is a collection of particles, and the particles interact during the search to solve a problem. The swarms are the complete population of the bird or fish and particle is each member in a population [9], [17-18]. During the optimum search of the swarm, the particles share information about their own experiences and previous experiences of all the other particles.

In this work the set of $\mathrm{K}_{\mathrm{p}}, \mathrm{K}_{\mathrm{i}}$, and $\mathrm{K}_{\mathrm{d}}$ values are considered as particles for optimizing the controller parameters for PID and I-PD controllers. After the completion of iterations, the particles move towards the optimum place in the three dimensional space problem, and results in best solution [19-20]. The flowchart of the PSO optimization algorithm is shown in Fig. 4. 


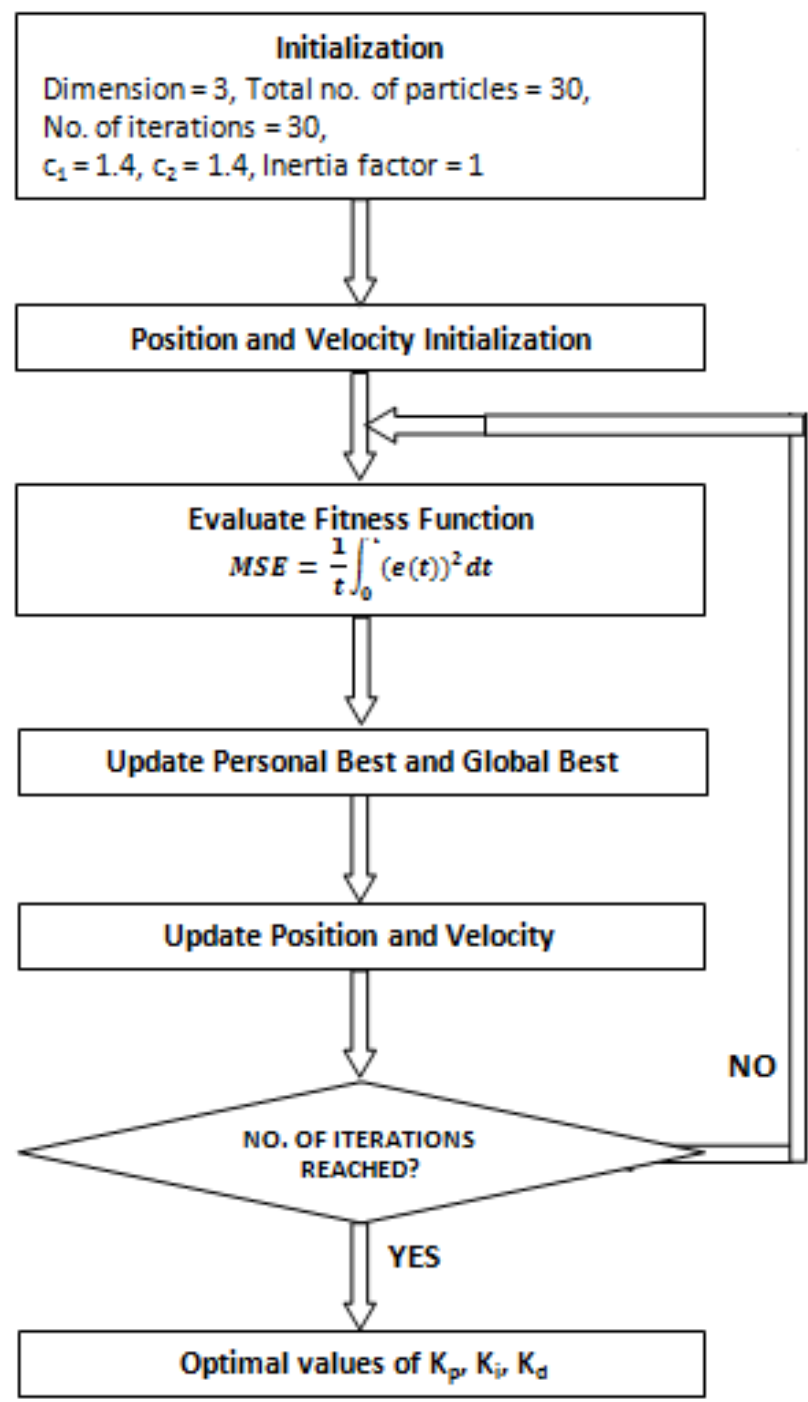

Fig. 4: Flowchart of PSO Optimization Algorithm

Initialization of swarm position and velocity are done based on the Equations 8 and 9.

Initialization of Position

$$
\mathrm{x}_{0}^{\mathrm{i}}=\mathrm{x}_{\min }+\operatorname{rand}^{*}\left(\mathrm{x}_{\max }-\mathrm{x}_{\min }\right)
$$

Initialization of Velocity

$$
\mathrm{v}_{0}^{\mathrm{i}}=0.1 * \operatorname{randn}(\operatorname{dim}, \mathrm{n})
$$

Where, $x_{\max } \& x_{\min }$ - Boundary of the position

$$
\begin{aligned}
& \text { dim - Dimension of the design space } \\
& \mathrm{n} \text { - No of particle }
\end{aligned}
$$

Updating the velocity and position

Velocity updation

$$
v_{\mathrm{k}+1}^{\mathrm{i}}=\mathrm{w}^{*} \mathrm{v}_{\mathrm{k}}^{\mathrm{i}}+\mathrm{c}_{1}^{*} \text { rand } 0^{*}\left(\mathrm{p}_{\mathrm{i}}-\mathrm{x}_{\mathrm{k}}^{\mathrm{i}}\right)+\mathrm{c}_{2} \operatorname{rand} \mathrm{O}^{*}\left(\mathrm{p}_{\mathrm{k}}^{\mathrm{g}}-\mathrm{x}_{\mathrm{k}}^{\mathrm{i}}\right)
$$

Where, w - Inertia factor (in between $0.4 \& 1.4$ )

$\mathrm{c}_{1}$ - Self confidence of the particle

$\mathrm{C}_{2}$ - Swarm confidence (in between 1 and 2) 
$\mathrm{p}_{\mathrm{i}}-$ Personal best

$p_{k}{ }^{g}$ - Global best

Position updation

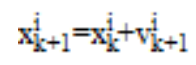

The PSO optimized PID and I-PD controller parameter gain values are given in the Table 2.

Table 2. PSO Tuned Controller Parameters

\begin{tabular}{|c|c|c|c|}
\hline \multirow{2}{*}{} & \multicolumn{3}{|c|}{ Controller Parameters } \\
\cline { 2 - 4 } & $\mathrm{K}_{\mathrm{p}}$ & $\mathrm{K}_{\mathrm{i}}$ & $\mathrm{K}_{\mathrm{d}}$ \\
\hline PSO PID & 7.2211 & 0.2151 & 34.8532 \\
\hline PSO I-PD & 7.5462 & 0.2181 & 31.5568 \\
\hline
\end{tabular}

It is found from the table that the proportional gain and integral gain values are marginally reduced and derivative gain is increased in I-PD controller compared to PID controller.

\section{RESULTS AND ANALYSIS}

The feasibility of improving the performance of different optimized controllers in control of cavity temperature of PIM is studied with computer simulation. The study also includes the comparison of performance indices like settling time and peak overshoot of ZN, Fuzzy, GA and PSO optimized PID and I-PD controllers. The response of the Cavity control system with PID controller and proposed I-PD controller are shown in Fig 5, and Fig 6.

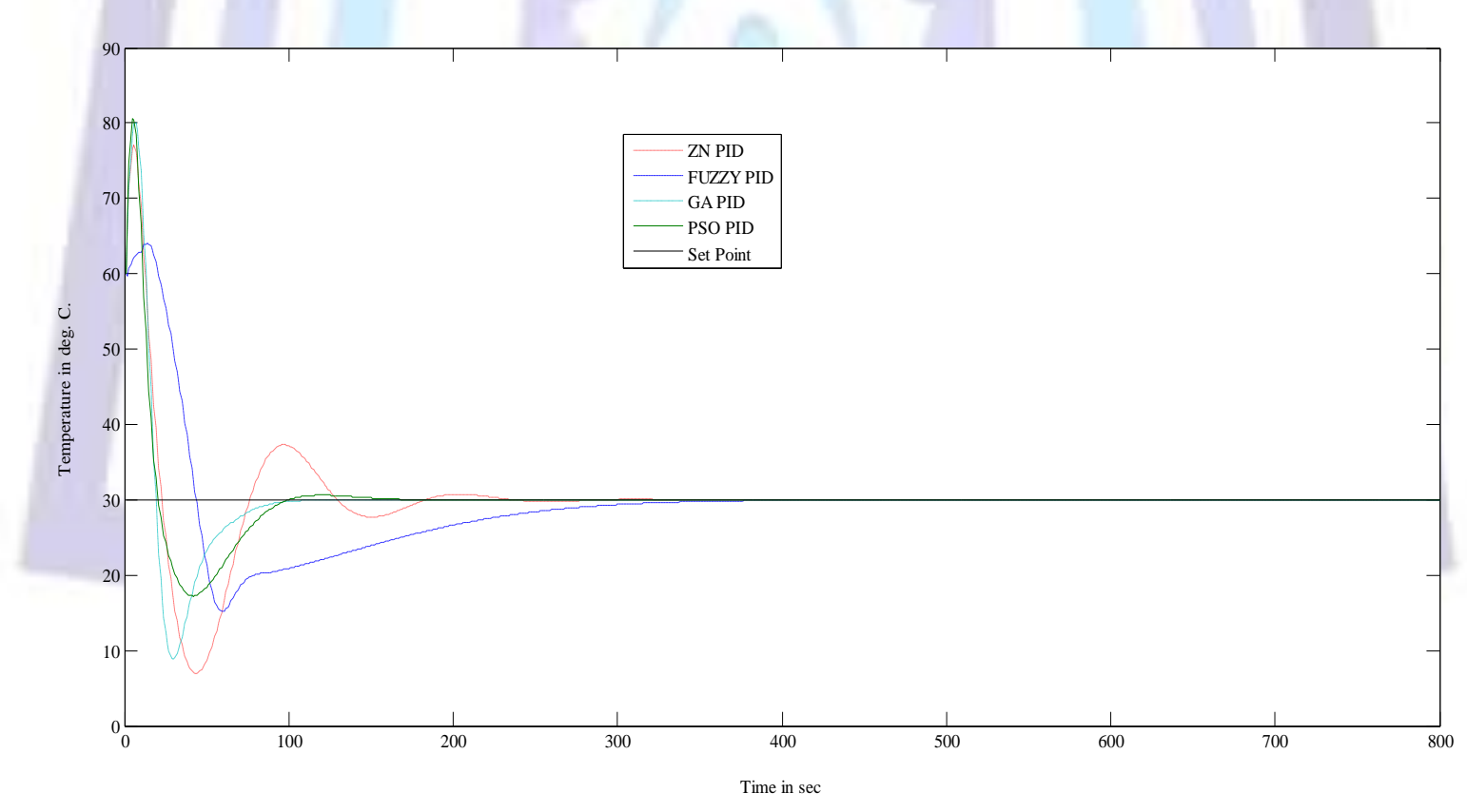

Fig. 5: Response of Cavity control system with PID controller 


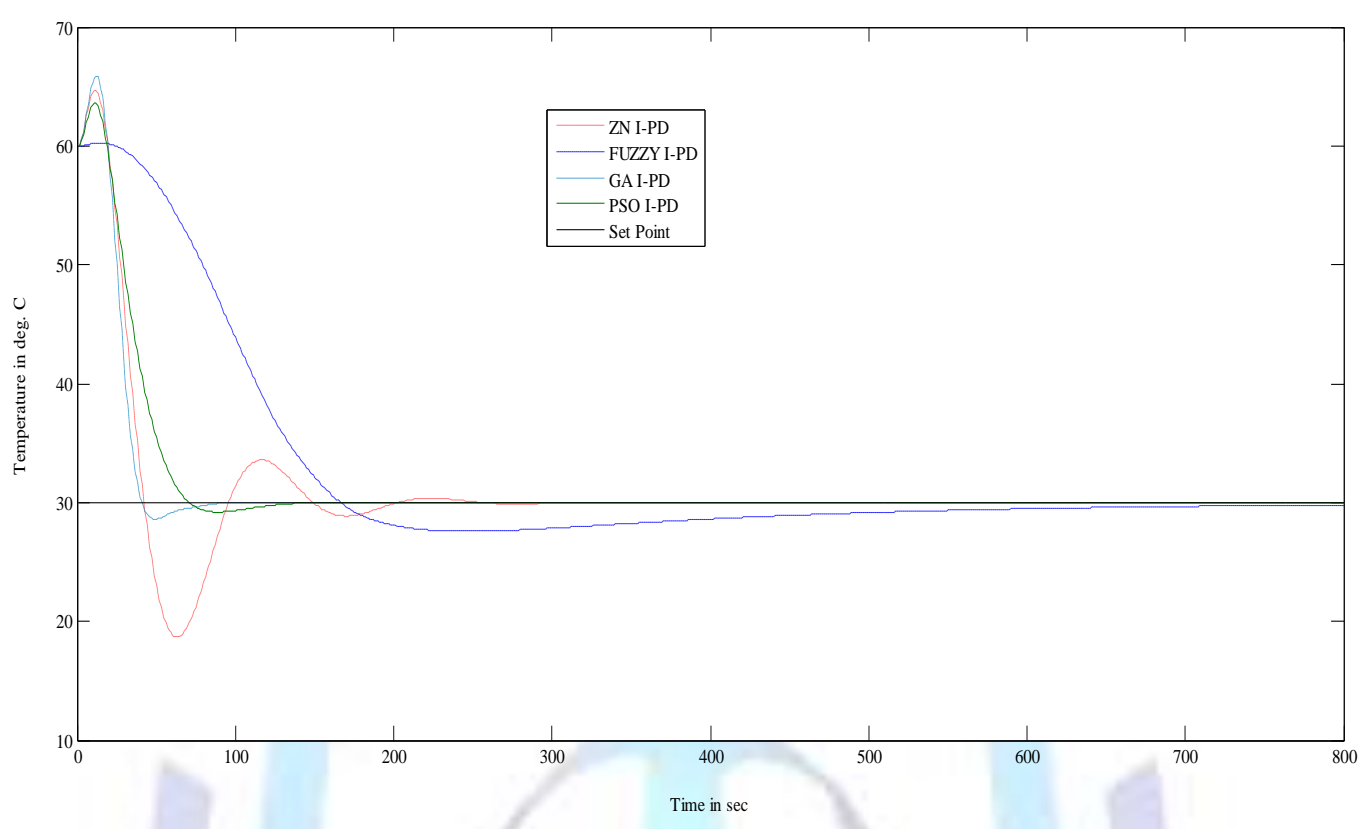

Fig. 6: Response of Cavity control system with I-PD controller

From the figures, it is observed that with ZN I-PD controller, the undershoot is reduced from $76.56 \%$ to $37.73 \%$ compared to ZN PID controller. The controller parameters obtained with the ZN tuning procedure do not provide a satisfactory response and so the evolutionary algorithm is used for the control of mold cavity control system. It is observed that the settling time of GA optimized I-PD controller is 3.73 minutes and it out performs than any other controllers for the selected application. The percentage peak undershoot is also considerably reduced to 2.65 percentage in PSO optimized I-PD controller compared to others. Table 3 shows the comparative analysis of performance indices of different controllers employed.

Table 3. Comparative Analysis of Performance Indices

\begin{tabular}{|c|c|c|c|}
\hline \multicolumn{2}{|c|}{ Performance Indices } & $\begin{array}{c}\text { Settling time } \\
\text { (min.) }\end{array}$ & $\begin{array}{c}\text { Undershoot } \\
\text { (\%) }\end{array}$ \\
\hline \multirow{2}{*}{ ZN } & PID & 12.5 & 76.56 \\
\cline { 2 - 4 } & I-PD & 12.07 & 37.73 \\
\hline \multirow{2}{*}{ Fuzzy } & PID & 12.4 & 49.2 \\
\cline { 2 - 4 } & I-PD & Offset & 8.07 \\
\hline \multirow{2}{*}{ GA } & PID & 4.1 & 70.5 \\
\cline { 2 - 4 } & I-PD & 3.73 & 4.63 \\
\hline \multirow{2}{*}{ PSO } & PID & 6.7 & 42.48 \\
\cline { 2 - 4 } & I-PD & 5.9 & 2.65 \\
\hline
\end{tabular}

The comparison of I-PD controller with different algorithms is shown in Fig.7. 


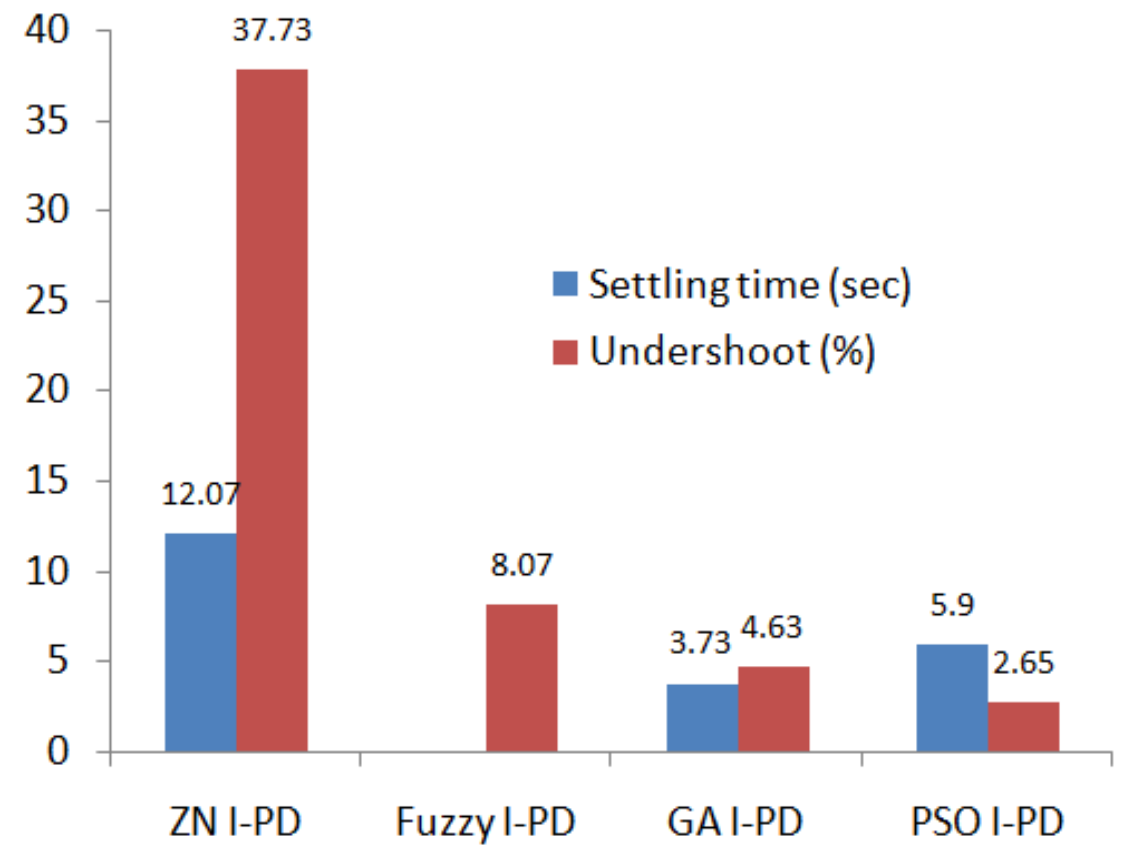

Fig.7: Comparison of I-PD controller with different algorithms

From the above figure it is inferred that undershoot present in ZN based I-PD controller is reduced to $5.9 \%$ in PSO based I-PD controller and the fuzzy based I-PD controller produces offset. The presence of undershoot may result in improper cooling of mold and, in turn, it would affect the product quality, but it is minimal in cavity temperature control with PSO based I-PD controller.

The settling time is improved with PSO based I-PD controller compared to all other selected methods which in improves the production rate of the molding machine. The robustness of the PSO I-PD controller is also checked with load disturbance rejection, which is depicted in Fig.8.

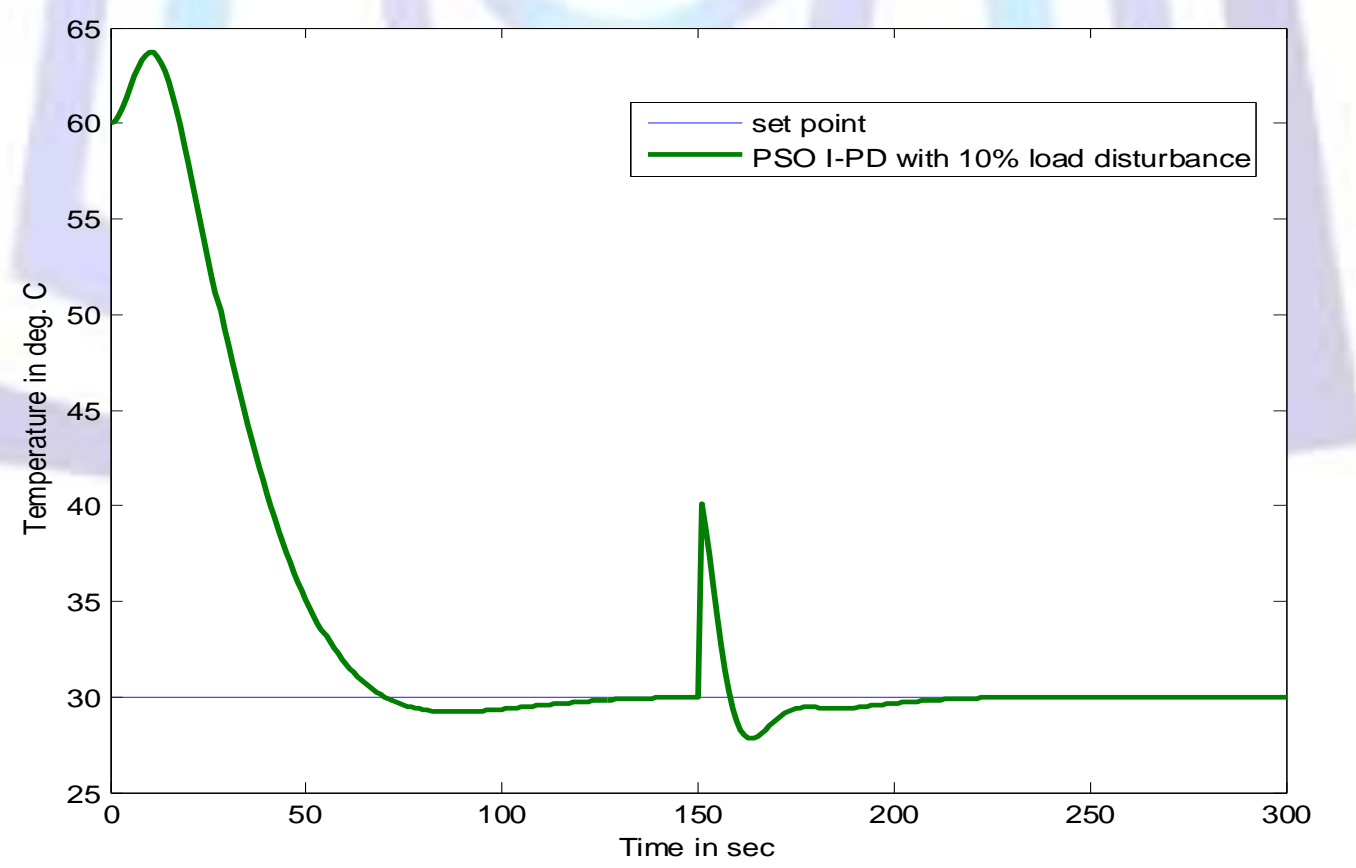

Fig. 8: Load disturbance rejection by PSO I-PD controller

From the above figure, it is observed that when $10 \%$ of load disturbance is given to the process, the cavity temperature control system with PSO I-PD controller rejects the disturbance within 86 seconds. 


\section{CONCLUSION}

The performance indices of the I-PD controller are improved with the proposed Particle Swarm Optimization for the PIM system under study. The undershoot is minimized to $2.65 \%$ compared to other methods. The settling time is reduced $9 \%$ in GA optimized I-PD controller compared to the GA PID controller and 12\% in PSO optimized I-PD controller compared to PSO PID controller. Hence it is concluded that the reduction in undershoot with PSO I-PD controller, preserves dimensional stability and mechanical properties of mold products in injection molding machine. The performance of the control system can be improved by adopting multi objective optimization and hybrid algorithm.

\section{REFERENCES}

1. Rickey Dubay, Bambang Pramujati, and Jose Hernandez, 2005, "Cavity Temperature Control in Plastic Injection Molding", IEEE International Conference on Mechatronics \& Automation, vol. 2, pp. 911-916.

2. Dubay R., Pramujati B., and Hernandez M., 2006,"A generic Controller for Part Surface Temperature on a Plastic Injection Molding Machine", Advances in Polymer Technology, vol. 25, no. 1, pp. 1-12.

3. Ke Yao, Furong Gao and Frank Allgower, 2008, "Barrel Temperature Control During Operation transition in Injection Molding", Control Engineering Practice, Science Direct, vol. 16, pp. 1259-1264.

4. Astrom J., and T. Hagglund, 2001, "The future of PID control", Control Engineering Practice, Science Direct, vol. 9, pp. 1163-1175.

5. Kiam Heong Ang, Gregory Chong and Yun Li, 2005, "PID Control System Analysis, Design, and Technology", IEEE Transactions on Control Systems Technology, vol. 13, no. 4, pp. 559-576.

6. Yun li, Kiam Heong Ang, and Gregory C.Y. Chong, 2006 "PID Control System Analysis and Design - Problems, Remedies and Future Directions", IEEE Control systems magazine, pp. 32-41.

7. "Amarendra Reddy B., Ram Charan K., Kranti Kiran Ankam, and Ramalingeswara Prasad K., 2010, "Control of Non-Linear Systems Using Parallel Structure of Fuzzy PI+PD Controller", International Journal of Engineering Science and Technology, vol. 2, no.8, pp. 3422-3433.

8. Vineetkumar, Nakra B. C., and Mittal. A. P., 2011, "A Review on Classical and Fuzzy PID Controllers", International Journal of Intelligent Control and Systems, vol. 16, no. 3, pp. 170-181.

9. Rania Hassan, BabakCohanim and Olivier de Weck, 2005, "A Comparison of Particle Swarm Optimization and the Genetic Algorithm", 46th AIAA/ASME/ASCE/AHS/ASC Structures, Structural Dynamics and Materials Conference, April 18-21.

10. Nagaraj B, P. Vijayakumar , 2011, "A Comparative Study Of PID Controller Tuning Using GA, EP, PSO AND ACO", Journal of Automation, Mobile Robotics \& Intelligent Systems, vol. 5, no. 2 pp. 42-48.

11. Aidan O"Dwyer, 2006, "Handbook of PI and PID Controller Tuning Rules", 2nd Edition, Imperial College Press.

12. Asim Ali Khan, and Nishkam Rapal, 2006, "Fuzzy PID Controller: Design, Tuning and Comparison with Conventional PID Controller", IEEE International Conference on Engineering of Intelligent Systems, pp.1-6.

13. SanthiPrabha I., DurgaRao K., and Siva Rama Krishna D., 2011, "Fuzzy Logic Based Intelligent Controller Design for an Injection Mould Machine Process Control", International Journal of Advanced Engineering Sciences and Technologies, vol. 10, pp. 098-103.

14. Mohammed Obaid Ali, S. P. Koh, K. H. Chong, S.K.Tiong, and ZeyadAssiObaid, 2009, "Genetic Algorithm Tuning Based PID Controller for Liquid-Level Tank System", Proceedings of the International Conference on ManMachine Systems (ICoMMS), 4A5-pp. 1-5.

15. Ayman A. Aly, 2011, "PID Parameters Optimization Using Genetic Algorithm Technique for Electrohydraulic Servo Control System", Intelligent Control and Automation, vol. 2, no. 2, pp. 69-76.

16. Mohd Sazli Saad, Hishamuddin Jamaluddin, and Intan Zaurah Mat Darus, 2012, " Implementation of PID Controller Tuning using Differential Evaluation and Genetic Algorithm”, International Journal of Innovative computing, information and Control, vol. 8, no. 11, pp. 7761-7779.

17. Russell C Eberhart and YuhuiShi, 2001, "Particle Swarm Optimization: Developments, Applications and Resources", Proceedings of the 2001 Congress on Evolutionary Computation, vol. 1, pp. 81-16.

18. Riccardo Poli ,James Kennedy and Tim Blackwell, 2007, "Particle swarm optimization-An overview", Springer Science, Business Media, vol.1, no.1, pp. 33-57.

19. Tushar Jain and M. J. Nigam., 2008, "Optimization of PD-PI Controller Using Swarm Intelligence", International Journal of Computational Cognition, vol. 6, no. 4, pp. 55-59.

20. Wen-wen Cai, Li-xinJia, Yan-bin Zhang,Nan Ni., 2010, "Design and Simulation of Intelligent PID Controller Based on Particle Swarm Optimization", IEEE International conference on E-Product Eservice and E-Entertainment (ICEEE), pp. 1-4, 2010. 